\title{
Demicellization of Polyethylene Oxide in Water Solution under Static Magnetic Field Exposure Studied by FTIR Spectroscopy
}

\author{
Emanuele Calabrò and Salvatore Magazù \\ Department of Physics, University of Messina, 98166 Messina, Italy \\ Correspondence should be addressed to Emanuele Calabrò; e.calabro@yahoo.com
}

Received 19 June 2013; Accepted 19 September 2013

Academic Editor: Sergei Tretiak

Copyright (C) 2013 E. Calabrò and S. Magazù. This is an open access article distributed under the Creative Commons Attribution License, which permits unrestricted use, distribution, and reproduction in any medium, provided the original work is properly cited.

\begin{abstract}
FTIR spectroscopy was used to investigate the alterations of the vibration bands in the mid-infrared region of Polyethylene oxide in aqueous solution at $25 \mathrm{mg} / \mathrm{mL}$ concentration under exposure up to $4 \mathrm{~h}$ to a static magnetic field at $200 \mathrm{mT}$. FTIR spectroscopic analysis of PEO solution in the range $3500-1000 \mathrm{~cm}^{-1}$ evidenced the stretching vibrations of ether band, C-H symmetricantisymmetric and bending vibrations of methylene groups, and the $\mathrm{C}-\mathrm{O}-\mathrm{C}$ stretching band. A significant decrease in intensity of symmetric and asymmetric stretching $\mathrm{CH}_{2}$ vibration bands occurred after $2 \mathrm{~h}$ and $4 \mathrm{~h}$ of exposure, followed by a significant decrease in intensity of scissoring bending in plane $\mathrm{CH}_{2}$ vibration around $1465 \mathrm{~cm}^{-1}$. Finally, the $\mathrm{C}-\mathrm{O}-\mathrm{C}$ stretching band around $1080 \mathrm{~cm}^{-1}$ increased in intensity after $4 \mathrm{~h}$ of exposure. This result can be attributed to the increase of formation of the intermolecular hydrogen bonding that occurred in PEO aqueous solution after SMF exposure, due to the reorientation of PEO chain after exposure to SMF. In this scenario, the observed decrease in intensity of $\mathrm{CH}_{2}$ vibration bands can be understood as well considering that the reorientation of PEO chain under the applied SMF induces PEO demicellization.
\end{abstract}

\section{Introduction}

Polymers are substances whose molecules have high molar masses, formed by repeated linking of small molecules called "monomers".

Some natural polymers are proteins, starches, cellulose, and latex. Synthetic polymers are produced commercially on a large scale and have a wide range of properties and uses, such as plastics. Water-soluble polymers may be used in industrial and consumer products such as polymeric surfactant, pigment dispersants, or detergents, due to their properties of assembly in spherical micelles and vesicles that may be used as drug delivery vehicles. Indeed, several polymers can aggregate in micelles and can be considered good candidates for drug delivery purposes [1-4].

An important property of polymers is crystallization. The long chains of repeating monomers of a polymer form stacks of parallel chains called lamellae, that fold back on itself, as explained by $[5,6]$. If crystallization is increased, the polymers tend to be stronger and more rigid, however this can lead to brittleness $[7,8]$.
Polymers structure have been accurately studied using neutron scattering techniques $[9,10]$.

In particular, the structure of polyethylene oxide (PEO) micelles is well described by the core-corona model [11-13] PEO crystallinity was found by [14].

PEO is one of the simplest polymers, composed of chains of repeating $-\mathrm{CH}_{2}-$ units, which is produced by the addition polymerization of ethylene; it is one of the most extensively studied water soluble polymers, because of the simplicity of its macromolecule's basic forming unit, the monomer $\mathrm{CH}_{2} \mathrm{CH}_{2} \mathrm{O}$.

PEO is biocompatible, it can inhibit protein adsorption and can replace some biopolymers providing an insight to their behavior and functions [15-17].

The interest of researchers was also focused on the use of polymers in biomedical applications $[18,19]$, so that polymers can be considered to have a fundamental role in human life.

In the last few years, an interest in the effects of electromagnetic fields (EMFs) on the physicochemical properties of polymers has increased due to various functions attributed to these materials, often used as devices for insulation from 
EMFs because their dielectrical properties. Indeed, although the conductivity of most polymers is low, more effects can be observed such as space charge and electrical breakdown strength [20].

Otherwise, the general population is commonly exposed to SMFs ranging from 0.1 to $10 \mathrm{mT}$, such as the magnetic flux density measured in proximity of the magnetic poles of conventional rail system DC traction motors, audio speaker components, battery-operated motors, refrigerator magnets, and headphones [21-23], whose effects on simple organic systems cannot be neglected [24-27].

It is only recently that the electrical characteristics of polymers have begun to be studied in detail, beginning an area of much interest besides their great mechanical properties. For instance, several elements of polymer materials are used in reactor materials and could be used in future fusion reactors, where magnetic confinement of plasma in a high induction static magnetic field (SMF) over $1 \mathrm{~T}$ have to be planned $[28,29]$. In particular, the necessary security conditions for these future reactors give rise to concerns about the actual insulation capacity of polymers.

Furthermore, some effects of SMFs on crystalline and semicrystalline polymers such as creep and decrease of mechanical properties like the modulus of elasticity were observed, giving proof that the mechanical properties of polymers can be changed under SMFs exposure [30-33].

Hence, it may be important to study polymers behavior under the external stress of a SMF.

PEO can be considered a useful organic system to study the response to external SMFs because of the simplicity of its macromolecule's basic forming unit $\mathrm{CH}_{2} \mathrm{CH}_{2} \mathrm{O}$.

The presence of an oxygen atom in PEO can change entirely the nature of the interactions when it is dissolved in various solvents.

PEO aqueous solution is characterized by hydrophobic and hydrophilic interactions as the $\mathrm{CH}_{2}$ groups repel water, whereas hydrogen bonding of water molecules to the oxygen atoms on the polymer is formed when PEO is dissolved in water. Indeed, the main difference between the commonly studied polyethylene and PEO is water solubility, due to the polar nature of $\mathrm{PEO}$.

PEO can dissolve in water because water molecules form a sheath around the PEO macromolecule by means of hydrogen bonding, whose model was extensively used to understand the mechanism of PEO solubility in water [3440].

All these considerations led us to investigate the effects of external SMFs on the vibration bands of PEO using Fourier Transform Infrared (FTIR) spectroscopy. Indeed, infrared spectroscopy have already been proved to be a powerful tool in the investigation of the water structures inside polymeric materials [40-43].

\section{Materials and Methods}

2.1. Materials. Polyethylene oxide, with $\mathrm{Mw}=600000$, was purchased from Sigma Aldrich (Milan, IT).
The polymer was dissolved at $25 \mathrm{mg} / \mathrm{mL}$ concentration in bidistilled $\mathrm{H}_{2} \mathrm{O}$ with gentle agitation at the room temperature of $20^{\circ} \mathrm{C}$.

Samples of $250 \mu \mathrm{L}$ of PEO aqueous solution were constituted at this concentration and immediately subjected to the following assays.

2.2. Experimental Design. The exposure system consisted of a couple of Helmholtz coils, with pole pieces of round parallel polar faces to produce a uniform magnetic field at the center of the coils distance, where the samples were placed, as described in [25]. A SMF was generated by coils powered by a DC generator, producing a uniform magnetic field intensity of $200 \mathrm{mT}$, corresponding to a half of the exposure limit for SMF recommended by the International Commission on Non-Ionizing Radiation Protection for public exposure [44].

Samples of PEO aqueous solution were placed at the centre of a uniform field area between the coils.

The magnetic field was continuously monitored by a magnetic field probe.

2.3. Infrared Spectroscopy. FTIR absorption spectra were recorded at room temperature by a spectrometer Vertex $80 \mathrm{v}$ of Bruker Optics.

PEO aqueous solution $(25 \mathrm{mg} / \mathrm{mL})$ samples were placed between a pair of $\mathrm{CaF}_{2}$ windows separated with a $25 \mu \mathrm{m}$ Teflon spacer. For each spectrum, 64 interferograms were collected and coadded by Fourier transformed employing a Happ-Genzel apodization function to generate a spectrum with a spectral resolution of $4 \mathrm{~cm}^{-1}$ in the range from $4000 \mathrm{~cm}^{-1}$ to $1000 \mathrm{~cm}^{-1}$. IR spectra of water solution were subtracted from the spectra of PEO solution at the corresponding temperature.

Each measure was performed under vacuum to eliminate minor spectral contributions due to residual water vapor, and smoothing correction for atmospheric water background was performed. IR spectra were baseline corrected and area normalized for exposed and control samples, using vector normalization, calculating the average value of the spectrum, and subtracting from the spectrum decreasing the midspectrum. The sum of the squares of all values was calculated and the spectrum divided by the square root of this sum, as accurately described in $[45,46]$.

Also, interactive baseline rubberband correction was used to subtract baselines from spectra, using a rubberband which is stretched from one spectrum end to the other, and the band is pressed onto the spectrum from the bottom up with varying intensity. This method is performed iteratively, depending on the number of iterations in the algorithm and the baseline as a frequency polygon consisting of $n$ baseline points. The resulted spectrum will be the original spectrum without the baselines points manually set and a subsequent concave rubberband correction. The values of 50 baseline points and 60 iterations were used.

2.4. Statistical Analysis. Exposures and measurements were repeated using 12 samples. Statistical analysis was carried out 


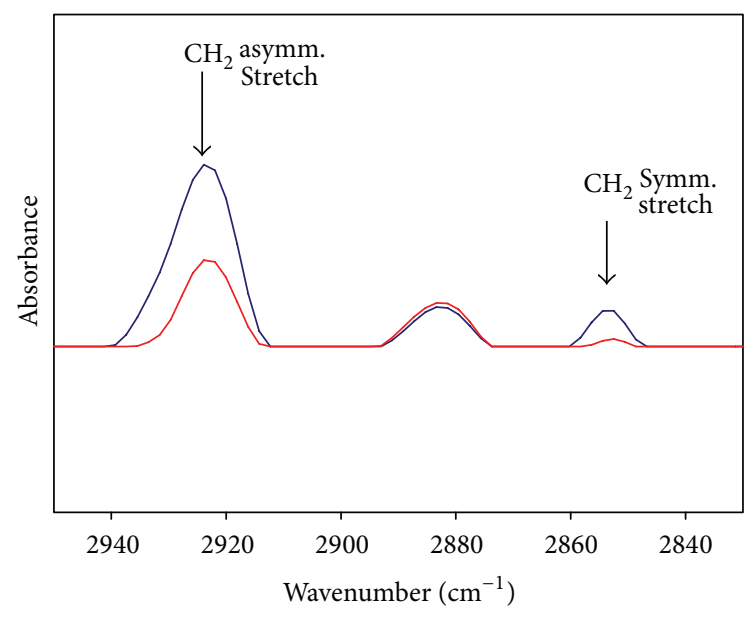

(a)

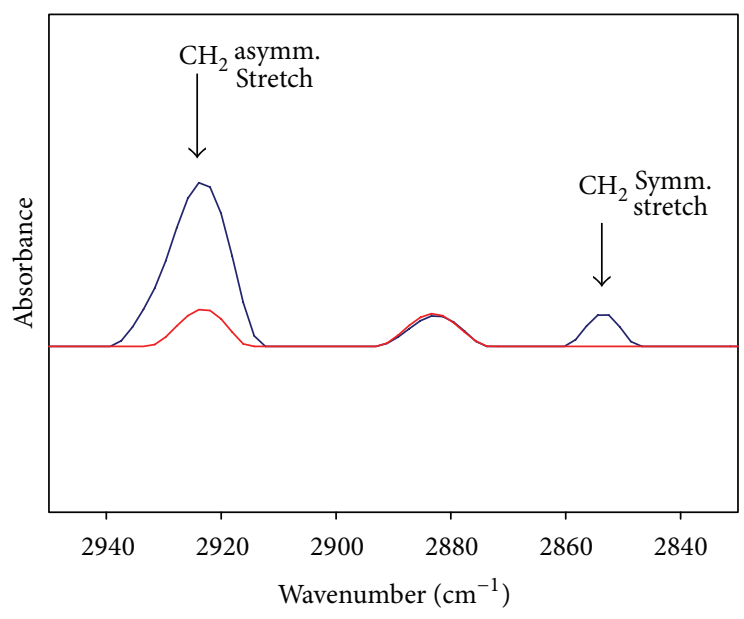

(b)

FIGURE 1: A representative spectrum in the region $3000-2800 \mathrm{~cm}^{-1}$ of PEO in bidistilled water solution. The vibration bands around 2850 and $2925 \mathrm{~cm}^{-1}$ (indicated by arrows) are due to the symmetric stretching and to the asymmetric stretching of the methylene group, respectively. Their intensity decreased significantly after exposure of $2 \mathrm{~h}(\mathrm{a})$ and $4 \mathrm{~h}(\mathrm{~b})$ to a SMF at $200 \mathrm{mT}$. The spectra of exposed and unexposed samples are represented by red and blue lines, respectively.

using Student's $t$-test for comparisons between two groups, with $P$ values less than 0.05 considered significant.

\section{Results and Discussion}

The vibration bands in the mid-infrared region of PEO in aqueous solution under SMFs exposure were studied using FTIR spectroscopic techniques to acquire further information about the dielectric properties of polymers as insulators from EMFs.

Different samples of $250 \mu \mathrm{L}$ of PEO in bidistilled water aqueous solution, prepared as described in the preceding section, were exposed up to 4 hours to a SMF at $200 \mathrm{mT}$ at the room temperature of $20^{\circ} \mathrm{C}$. Analogue unexposed samples were used as control, at the same temperature.

FTIR spectra acquired after $2 \mathrm{~h}$ and $4 \mathrm{~h}$ of exposure showed significant changes of vibration bands in comparison to control, as described below. No further change occurred after exposure of more than $4 \mathrm{~h}$.

Measurements were repeated ten times to ensure the statistical significance of results.

Representative exposed and unexposed FTIR spectra in the region $2800-3000 \mathrm{~cm}^{-1}$ obtained after $2 \mathrm{~h}$ and $4 \mathrm{~h}$ of exposure are shown in Figures 1(a) and 1(b), respectively.

Two relevant vibration bands appeared to change in that range: the bands around $2850 \mathrm{~cm}^{-1}$ and $2925 \mathrm{~cm}^{-1}$, due to the symmetric stretching $\left({ }^{s} \mathrm{CH}_{2}\right)$ and to the asymmetric stretching $\left({ }^{\mathrm{as}} \mathrm{CH}_{2}\right)$ of the methylene group, respectively [4749].

The intensity of $\mathrm{CH}_{2}$ stretching bands was observed to decrease significantly after exposure and to shift to lower frequencies; as can be observed in Figure 1, the decreases in intensity of $\mathrm{CH}_{2}$ bands after exposure of $2 \mathrm{~h}$ (a) and $4 \mathrm{~h}$ (b) were significantly different in comparison to controls
$(P<0.05)$. Exposed and unexposed samples spectra are represented by the red and blue lines, respectively.

Vibration bands of $\mathrm{CH}_{2}$ group can be observed at higher wavelength. In fact, bending vibrations of $\mathrm{CH}_{2}$ group are foreseen at lower frequencies than corresponding stretching vibrations, as both the stretching and bending vibrations of a molecule can be predicted mathematically (at least to a useful approximation by Hooke's law).

The strong vibration bands around $1465 \mathrm{~cm}^{-1}$, represented in Figures 2(a) and 2(b), that appear splitted into two bands, can be assigned at $\mathrm{CH}_{2}$ scissoring vibration bands [4749]. Also this band was observed to decrease after $2 \mathrm{~h}$ and $4 \mathrm{~h}$ of exposure, confirming the decrease of $\mathrm{CH}_{2}$ group due to exposure to SMF.

The strong band at $1349 \mathrm{~cm}^{-1}$ can be assigned to $\mathrm{CH}_{2}$ wagging vibration, and it is related to the $\mathrm{EO}$ methylene wagging vibrations of the gauche conformation, whereas the weak band at $1250 \mathrm{~cm}^{-1}$ may be related to $\mathrm{CH}_{2}$ twisting mode, both of which are characteristic of the amorphous state [5052].

A weak increase in intensity of these vibrations was observed after exposure to SMF, as represented in the typical spectra in Figure 2.

This alteration indicated that gauche conformation of EO segments increased, suggesting a decrease of the PEO crystallization process during exposure.

Otherwise, the hydrogen-bond model has been extensively used to interpret the mechanism of the solubility of water in oxyethylene type surfactants and polymers $[36,39$, $53,54]$.

Hydrogen bonded C-O groups changed accordingly with methylene groups of gauche conformation, following Noda's rule $[55,56]$.

This hypothesis is confirmed by the observed increase in intensity of the vibration band around $1080 \mathrm{~cm}^{-1}$ (see 


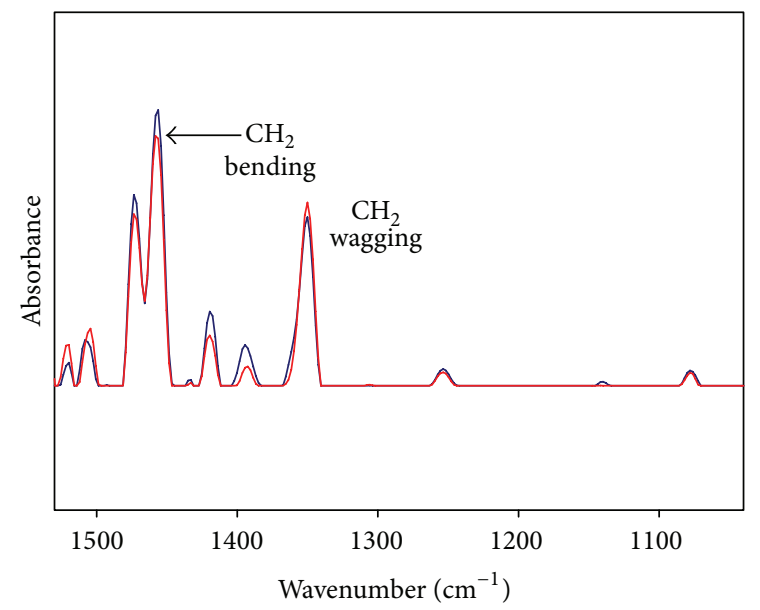

(a)

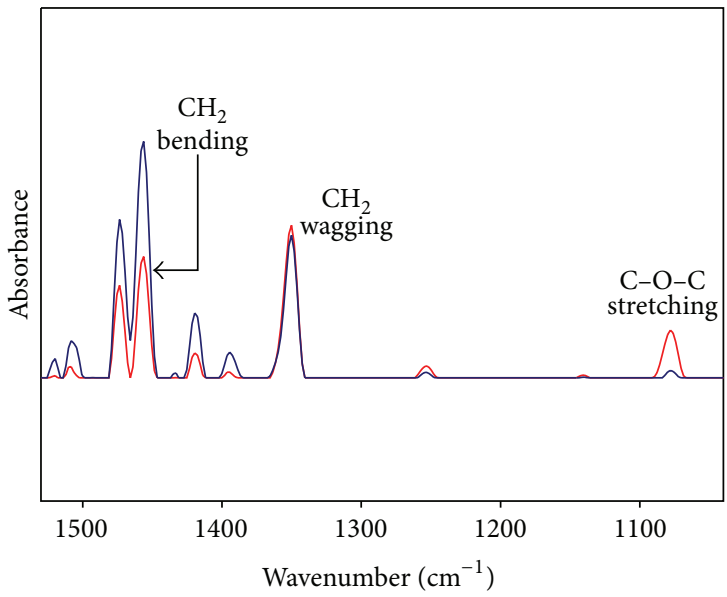

(b)

FIGURE 2: Representative spectra in the region $1500-1000 \mathrm{~cm}^{-1}$ of PEO in water solution after $2 \mathrm{~h}$ (a) and $4 \mathrm{~h}$ (b) of exposure to a SMF at $200 \mathrm{mT}$. The strong vibration band around $1465 \mathrm{~cm}^{-1}$ is splitted in two bands and can be assigned to $\mathrm{CH}_{2}$ scissoring vibration bands. The $1349 \mathrm{~cm}^{-1}$ peak is related to the EO methylene wagging vibrations of the gauche conformation. The strong band around $1080 \mathrm{~cm}^{-1} \mathrm{can} \mathrm{be}$ assigned to the $\mathrm{C}-\mathrm{O}-\mathrm{C}$ stretching hydrated bond. Red and blue lines refer to exposed and unexposed samples, respectively.

Figure 2(b)), which can be assigned to the $\mathrm{C}-\mathrm{O}-\mathrm{C}$ stretching vibration $[41,42,52]$.

The formation of a hydrogen bond Lone pair electrons on the oxygen atoms are withdrawn by the hydrogen atoms of water due to the formation of hydrogen bonds. This mechanism induces a reduction of electron density on the C$\mathrm{O}$ bond which generates a red shift of the $\mathrm{C}-\mathrm{O}-\mathrm{C}$ stretching band from 1113 to about $1080 \mathrm{~cm}^{-1}$ [39, 52,57].

Indeed, hydrogen bond weakens chemical bonds between atoms and therefore it produces shifts to lower frequencies and broadening in absorption bands.

The band at $1080 \mathrm{~cm}^{-1}$ represents the strongest band of the $\mathrm{C}-\mathrm{O}-\mathrm{C}$ linkages.

The bandwidth broadening of this vibration indicates that the polymer in aqueous solution have higher mobility [57]; its increase after exposure in comparison to unexposed samples showed that SMF increases PEO mobility in aqueous solution.

Also, $\mathrm{C}-\mathrm{O}-\mathrm{C}$ stretching band resulted in an to increase in intensity after exposure to SMF, and this change after $4 \mathrm{~h}$ exposure was significantly different in comparison to controls $(P<0.01)$.

In contrast, the dehydration in the micellization process could be inferred by the FTIR spectral analysis from a low shift of the frequency of the C-O-C stretching band toward higher wavenumbers.

The observed increase of the carbonyl stretching vibration C-O-C around $1080 \mathrm{~cm}^{-1}$ after exposure to SMF can be attributed to the increase of formation of the intermolecular hydrogen bonding that occurred in PEO aqueous solution after exposure.

This result is in well accordance with the increase of the weak band around $1140 \mathrm{~cm}^{-1}$ observed after $4 \mathrm{~h}$ of exposure to
SMF (see Figure 2(b)), that can be assigned to the dehydrated $\mathrm{C}-\mathrm{O}-\mathrm{C}$ bond $[58,59]$.

In this scenario, the decrease in intensity of stretching and scissoring vibrations of the methylene group that was observed after exposure to SMF can also be explained assuming that an unfolding of PEO chain occurred after exposure.

The application of a magnetic field on liquid-crystalline materials induces alignment of polymer molecules chains along the direction of a SMF [60].

Indeed, magnetic orientation can be applicable to materials such as macromolecules like polymers, composed by a relevant number of coupled molecules, so that a magnetic torque can induce molecular orientation effects [61].

Molecular dynamics simulations for the polyethylene chain was performed by [62] to study the polymer chain unfolding and reorientation processes under a high SMF, showing that it facilitates the unfolding of the flexible polyethylene chains and their reorientation in its direction.

Indeed, it was showed by [62] that the extra potential energy gained through the magnetic annealing of the chains can induce the reorientation of the polyethylene chains toward the direction of the magnetic field.

This "induced-unfolding" of PEO chain contrasts the micellization process through which the hydrophilic head of the polymer is in contact with solvent, and the hydrophobic tail (represented by the $\mathrm{CH}_{2}$ group) is sequestered within the micelle core.

In fact, as water is added to form $\mathrm{PEO}$ aqueous solution, the hydrophobic block $\mathrm{CH}_{2}$ is insoluble and collapses to form the micelle core, and it is encapsulated into the micelles.

Surfactants molecules which contain more than $16-\mathrm{CH}_{2}$ groups are stated to coil around themselves [63]. This mechanism produces aggregation of unimers, and successively the 


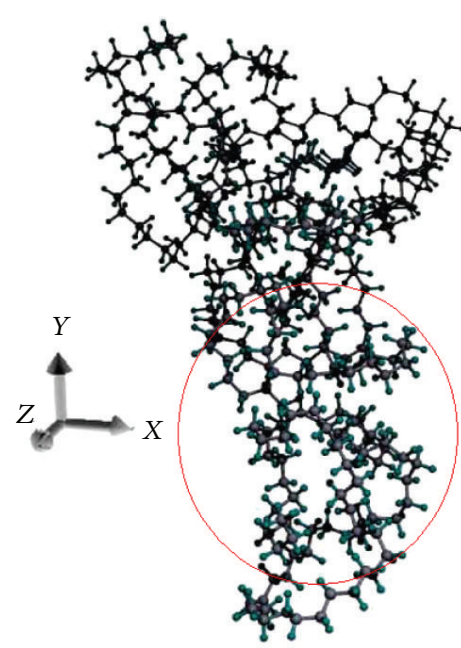

$1 \mathrm{fs}$

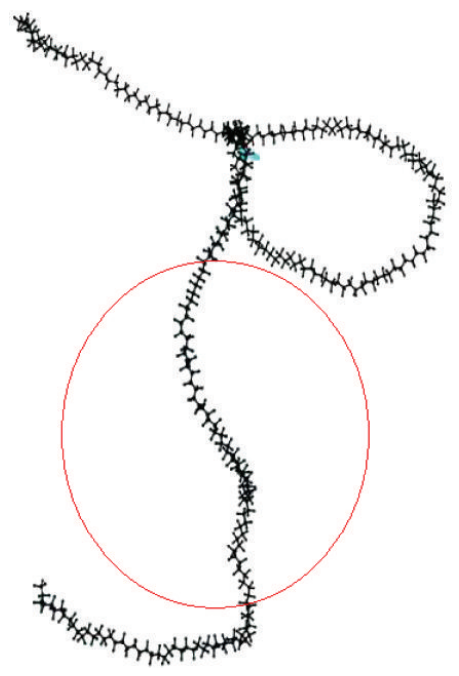

$1000 \mathrm{fs}$

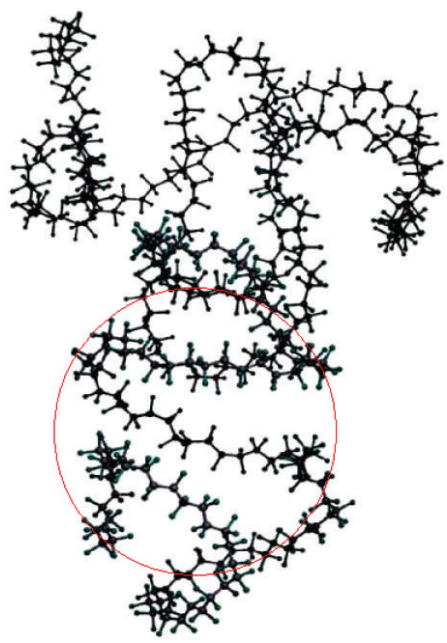

$200 \mathrm{fs}$

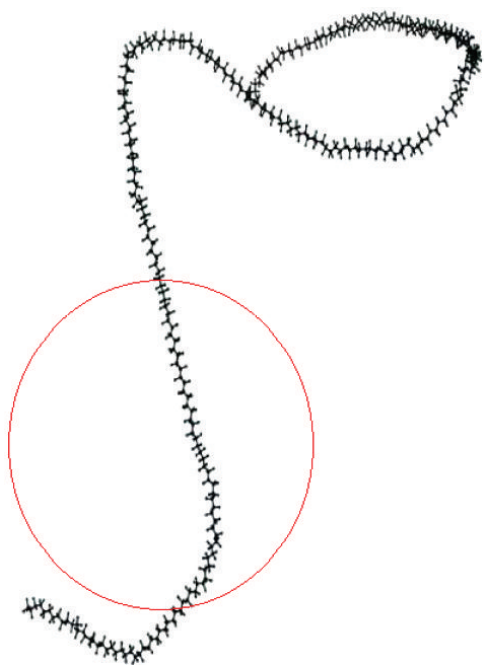

$2500 \mathrm{fs}$

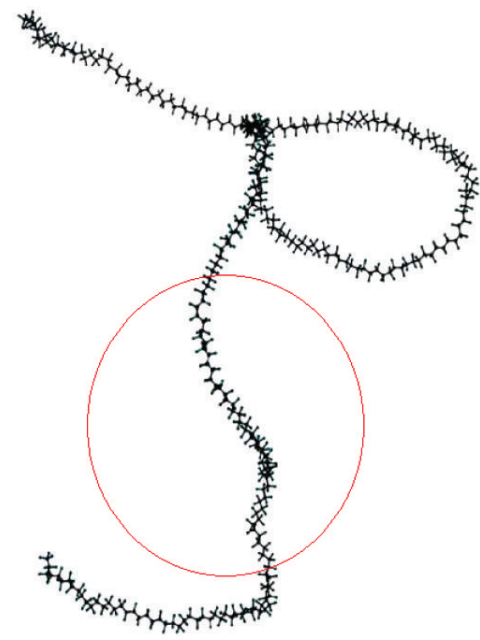

$500 \mathrm{fs}$

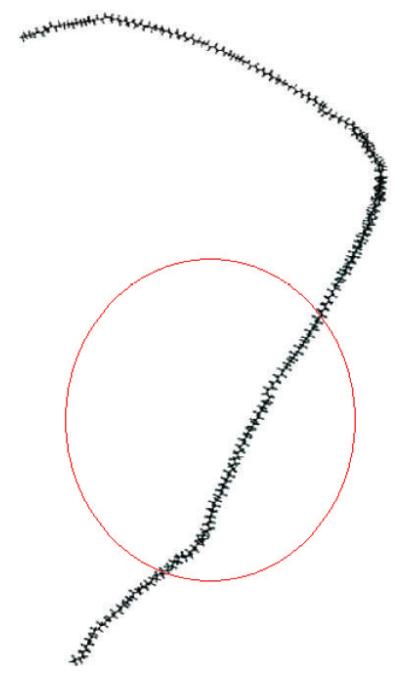

$5000 \mathrm{fs}$

Figure 3: Molecular dynamics simulation of reorientation of polyethylene chains under a high magnetic field at different time steps. The red circles schematize a fixed volume to highlight that the population of $\mathrm{CH}_{2}$ decrease as a function of time exposure. With kind permission of Taylor \& Francis Ltd (http://www.tandfonline.com/doi/abs/10.1080/08927020600887781).

polar conformation of EO segments tends to transform to nonpolar conformation.

The dehydrated methylene groups approach through the hydrophobic interaction to form hydrophobic cores, leading to a further breaking of the hydrogen bonding between $\mathrm{C}-\mathrm{O}$ and the water, and micelles are formed proportionally to the temperature value [64].

The micellization of PEO in water solution produces an increase of density of $\mathrm{CH}_{2}$ within a fixed volume, whereas the reorientation of $\mathrm{PEO}$ chain generated by the applied SMF induces its demicellization and the consequent decrease of $\mathrm{CH}_{2}$ density within the corresponding volume.
A decrease in intensity of $\mathrm{CH}_{2}$ vibration bands in the FTIR spectra is expected, corresponding to PEO demicellization, because the oscillator strength of a given spectral transition depends on a number of factors including population or occupancy. Hence, the modeling of PEO reorientation induced by exposure to SMF is in agreement with the decrease in intensity of $\mathrm{CH}_{2}$ stretching and bending vibrations observed after exposure, that can be explained by the decrease of population of $\mathrm{CH}_{2}$ within a fixed volume, well represented in Figure 3 (derived from the simulation of [62]).

In this scenario, the increase of formation of the intermolecular hydrogen bonding in PEO aqueous solution, 
observed after exposure to SMF, can find its explanation as well, because the reorientation of PEO chain under SMF can increase the surface contact of the hydrophilic head with aqueous solvent.

FTIR spectra of exposed samples were acquired $3 \mathrm{~h}$ after the end of exposure to SMF, showing that reversibility in the molecular vibrations of PEO occurs when the SMF is removed.

\section{Conclusion}

Exposure to a SMF at $200 \mathrm{mT}$ of samples of $\mathrm{PEO}$ in aqueous solution induced its demicellization as evidenced by FTIR spectroscopy analysis.

Indeed, a significant decrease in intensity of symmetric and asymmetric stretching $\mathrm{CH}_{2}$ vibration bands around 2925 and $2850 \mathrm{~cm}^{-1}$, respectively, was observed after $2 \mathrm{~h}$ and $4 \mathrm{~h}$ of exposure. The decrease of $\mathrm{CH}_{2}$ group was confirmed by the decrease of the scissoring vibration bands around $1465 \mathrm{~cm}^{-1}$. This result can be attributed to a demicellization of PEO in water due to the reorientation of PEO chain induced by the applied SMF.

An increase of methylene wagging vibration at $1349 \mathrm{~cm}^{-1}$ was observed after exposure to SMF, that can be related to a decrease of PEO crystallization process during exposure, in agreement with previous results.

The C-O-C stretching band around $1080 \mathrm{~cm}^{-1}$ was observed to increase significantly after $4 \mathrm{~h}$ of exposure to SMF; and this result can be attributed to the increase of intermolecular hydrogen bonding occurred in $\mathrm{PEO}$ aqueous solution, in agreement with the demicellization process.

These experimental results are in agreement with molecular dynamics simulations for the polyethylene chain performed by other authors.

\section{References}

[1] F. Meng, Z. Zhong, and J. Feijen, "Stimuli-responsive polymersomes for programmed drug delivery," Biomacromolecules, vol. 10, no. 2, pp. 197-209, 2009.

[2] R. P. Brinkhuis, F. P. J. T. Rutjes, and J. C. M. Van Hest, "Polymeric vesicles in biomedical applications," Polymer Chemistry, vol. 2, no. 7, pp. 1449-1462, 2011.

[3] S. B. La, T. Okano, and K. Kataoka, "Preparation and characterization of the micelle-forming polymeric drug: indomethacinincorporated poly(ethylene oxide)-poly(b-benzyl L-aspartate) block copolymer micelles," Journal of Pharmaceutical Sciences, vol. 85, p. 85, 1996.

[4] T. Riley, T. Govender, S. Stolnik et al., "Colloidal stability and drug incorporation aspects of micellar-like PLA-PEG nanoparticles," Colloids and Surfaces B, vol. 16, no. 1-4, pp. 147-159, 1999.

[5] A. Keller, "A note on single crystals in polymers-evidence for a folded chain configuration," Philosophical Magazine, vol. 2, no. 21, pp. 1171-1175, 1957.

[6] P. H. Till, "The growth of single crystals of linear polyethylene," Journal of Polymer Science, vol. 24, pp. 301-306, 1957.

[7] K. G. McLaren, "Dynamic mechanical studies of irradiation effects in polytetrafluoroethylene," British Journal of Applied Physics, vol. 16, no. 2, article no. 311, pp. 185-193, 1965.
[8] H. S. Kaufman and J. J. Falcetta, Introduction to Polymer Science and Technology: An SPE Textbook, Wiley \& Sons, 1977.

[9] S. Magazù, "NMR, static and dynamic light and neutron scattering investigations on polymeric aqueous solutions," Journal of Molecular Structure, vol. 523, no. 1-3, pp. 47-59, 2000.

[10] S. Magazù, G. Maisano, F. Migliardo, and A. Benedetto, "Elastic incoherent neutron scattering on systems of biophysical interest: mean square displacement evaluation from self-distribution function," Journal of Physical Chemistry B, vol. 112, no. 30, pp. 8936-8942, 2008.

[11] P. Alexandridis, J. F. Holzwarth, and T. A. Hatton, "Micellization of poly(ethylene oxide)-poly(propylene oxide)-poly(ethylene oxide) triblock copolymers in aqueous solutions: thermodynamics of copolymer association," Macromolecules, vol. 27, no. 9, pp. 2414-2425, 1994.

[12] M. Bohorquez, C. Koch, T. Trygstad, and N. Pandit, "A study of the temperature-dependent micellization of pluronic F127," Journal of Colloid and Interface Science, vol. 216, no. 1, pp. 3440, 1999.

[13] G. Wanka, H. Hoffmann, and W. Ulbricht, "Phase diagrams and aggregation behavior of poly(oxyethylene)poly(oxypropylene)-poly(oxyethylene) triblock copolymers in aqueous solutions," Macromolecules, vol. 27, no. 15, pp. 4145-4159, 1994

[14] J. Q. G. Maclaine and C. Booth, "Effect of molecular weight on crystallization isotherms of high molecular weight poly(ethylene oxide) fractions," Polymer, vol. 16, no. 9, pp. 680684, 1975.

[15] J. H. Lee, H. B. Lee, and J. D. Andrade, "Blood compatibility of polyethylene oxide surfaces," Progress in Polymer Science, vol. 20, no. 6, pp. 1043-1079, 1995.

[16] C. Allen, D. Maysinger, and A. Eisenberg, "Nano-engineering block copolymer aggregates for drug delivery," Colloids and Surfaces B, vol. 16, no. 1-4, pp. 3-27, 1999.

[17] B. M. Discher, Y.-Y. Won, D. S. Ege et al., "Polymersomes: tough vesicles made from diblock copolymers," Science, vol. 284, no. 5417, pp. 1143-1146, 1999.

[18] V. P. Torchilin, "Polymeric micelles for therapeutic applications in medicine," Nanoscience and Nanotechnology, vol. 9, pp. 261299, 2010.

[19] A. S. Mikhail and C. Allen, "Block copolymer micelles for delivery of cancer therapy: transport at the whole body, tissue and cellular levels," Journal of Controlled Release, vol. 138, no. 3, pp. 214-223, 2009.

[20] T. Blythe and D. Bloor, Electrical Properties of Polymers, Cambridge University Press, 2005.

[21] P. Chadwick and F. Lowes, "Magnetic fields on British trains," Annals of Occupational Hygiene, vol. 42, no. 5, pp. 331-335, 1998.

[22] World Health Organization (WHO), Static Fields. Environmental Health Criteria, WHO, Geneva, Switzerland, 2006.

[23] E. Calabrò, Effects of Electromagnetic Fields on Cells and Proteins' Structure, Lambert Academic Publishing, Saarbrücken, Germany, 2012.

[24] S. Magazù and E. Calabrò, "Studying the electromagneticinduced changes of the secondary structure of bovine serum albumin and the bioprotective effectiveness of trehalose by Fourier transform infrared spectroscopy," Journal of Physical Chemistry B, vol. 115, no. 21, pp. 6818-6826, 2011.

[25] S. Magazù, E. Calabrò, S. Campo, and S. Interdonato, "New insights into bioprotective effectiveness of disaccharides: an FTIR study of human haemoglobin aqueous solutions exposed 
to static magnetic fields," Journal of Biological Physics, vol. 38, no. 1, pp. 61-74, 2012.

[26] E. Calabrò, S. Condello, S. Magazù, and S. Ientile, "Static and $50 \mathrm{~Hz}$ electromagnetic fields effects on human neuronal-like cells vibration bands in the mid-infrared region.," Journal of Electromagnetic Analysis \& Applications, vol. 3, no. 2, pp. 69-78, 2011.

[27] S. Pacini, M. Gulisano, B. Peruzzi et al., "Effects of $0.2 \mathrm{~T}$ static magnetic field on human skin fibroblasts," Cancer Detection and Prevention, vol. 27, no. 5, pp. 327-332, 2003.

[28] W. Mauer, "In insulators for fusion applications," IAEATECDOC-417, International Atomic Energy Agency, Karlsruhe, Germany, 1986.

[29] P. A. Alexandrov, V. V. Budaragin, M. N. Shachov, N. I. Nikanorova, and E. S. Trofimchuk, "Mechanic properties of some materials in magnetic field, problems of atomic science and technology," Thermonuclear Synthesis, vol. 1, pp. 24-30, 2006.

[30] Y. P. Rodin, "Static magnetic fields and physical-mechanical properties of polymers. A review," Mechanics of Composite Materials, vol. 27, no. 3, pp. 331-341, 1991.

[31] I. Reinholds, V. Kalkis, and R. D. Maksimovs, "The effect of ionizing radiation and magnetic field on deformation properties of high density polyethylene/acrylonitrile-butadiene composites," Journal of Chemistry and Chemical Engineering, vol. 6, pp. 242249, 2012.

[32] N. N. Peschanskaya and P. N. Yakushev, "Polymer creep in a static magnetic field," Physics of the Solid State, vol. 39, no. 9, pp. 1509-1511, 1997.

[33] R. I. Reinholds I., V. Kalkis, R. D. Maksimov, J. Zicans, and R. M. Meri, "The effect of radiation modification and of a uniform magnetic field on the deformation properties of polymer composite blends," Mechanics of Composite Materials, vol. 47, no. 5, pp. 497-504, 2011.

[34] S. Saeki, N. Kuwahara, M. Nakata, and M. Kaneko, "Upper and lower critical solution temperatures in poly (ethylene glycol) solutions," Polymer, vol. 17, no. 8, pp. 685-689, 1976.

[35] Y. C. Bae, S. M. Lambert, D. S. Soane, and J. M. Prausnitz, "Cloud-point curves of polymer solutions from thermooptical measurements," Macromolecules, vol. 24, no. 15, pp. 4403-4407, 1991.

[36] S. Lüsse and K. Arnold, "The interaction of poly(ethylene glycol) with water studied by $1 \mathrm{H}$ and $2 \mathrm{H}$ NMR relaxation time measurements," Macromolecules, vol. 29, no. 12, pp. 4251-4257, 1996.

[37] S. Bekiranov, R. Bruinsma, and P. Pincus, "Solution behavior of polyethylene oxide in water as a function of temperature and pressure," Physical Review E, vol. 55, no. 1, pp. 577-585, 1997.

[38] G. D. Smith, D. Bedrov, and O. Borodin, "Molecular dynamics simulation study of hydrogen bonding in aqueous poly(ethylene oxide) solutions," Physical Review Letters, vol. 85, no. 26, pp. 5583-5586, 2000.

[39] T. Inoue, M. Matsuda, Y. Nibu, Y. Misono, and M. Suzuki, "Phase behavior of heptaethylene glycol dodecyl ether and its aqueous mixture revealed by DSC and FT-IR spectroscopy," Langmuir, vol. 17, no. 6, pp. 1833-1840, 2001.

[40] T. Inoue, H. Kawamura, M. Matsuda, Y. Misono, and M. Suzuki, "FT-IR and ESR spin-label studies of mesomorphic phases formed in aqueous mixtures of heptaethylene glycol dodecyl ether," Langmuir, vol. 17, no. 22, pp. 6915-6922, 2001.
[41] Y. Peng, P. Wu, and Y. Yang, "Two-dimensional infrared correlation spectroscopy as a probe of sequential events in the diffusion process of water in poly( $\varepsilon$-caprolactone)," Journal of Chemical Physics, vol. 119, no. 15, pp. 8075-8079, 2003.

[42] J. Umemura, D. G. Cameron, and H. H. Mantsch, "An FTIR study of micelle formation in aqueous sodium $n$-hexanoate solutions," Journal of Physical Chemistry, vol. 84, no. 18, pp. 2272-2277, 1980.

[43] Y. Maeda, T. Nakamura, and I. Ikeda, "Changes in the hydration states of poly(N-alkylacrylamide)s during their phase transitions in water observed by FTIR spectroscopy," Macromolecules, vol. 34, no. 5, pp. 1391-1399, 2001.

[44] International Commission on Non-Ionizing Radiation Protection (ICNIRP), "Guidelines on limits of exposure to static magnetic fields," Health Physics, vol. 96, pp. 504-514, 2009.

[45] S. Condello, E. Calabrò, D. Caccamo et al., "Protective effects of agmatine in rotenone-induced damage of human SH-SY5Y neuroblastoma cells: Fourier transform infrared spectroscopy analysis in a model of Parkinson's disease," Amino Acids, vol. 42, no. 2-3, pp. 775-781, 2012.

[46] E. Calabrò and S. Magazù, "Inspections of mobile phone microwaves effects on proteins secondary structure by means of Fourier transform infrared spectroscopy," Journal of Electromagnetic Analysis \& Applications, vol. 2, no. 11, pp. 607-617, 2010.

[47] F. S. Parker, Applications of Infrared Spectroscopy in Biochemistry, Biology, and Medicine, Plenum Press, New York, NY, USA, 1971.

[48] B. Rigas, S. Morgello, I. S. Goldman, and P. T. T. Wong, "Human colorectal cancers display abnormal Fourier-transform infrared spectra," Proceedings of the National Academy of Sciences of the United States of America, vol. 87, no. 20, pp. 8140-8144, 1990.

[49] B. Stuart, Biological Applications of Infrared Spectroscopy, Analytical Chemistry by Open Learning, John Wiley \& Sons, Chichester, UK, 1997.

[50] J. Bertie and D. Othen, "On the assignment of the infrared spectrum of ethylene oxide," Canadian Journal of Chemistry, vol. 51, pp. 1155-1158, 1973.

[51] D. V. Radziuk and H. Möhwald, "Spectroscopic investigation of composite polymeric and monocrystalline systems with ionic conductivity," Polymers, vol. 3, no. 2, pp. 674-692, 2011.

[52] M. A. K. L. Dissanayake and R. Frech, "Infrared spectroscopic study of the phases and phase transitions in poly(ethylene oxide) and poly(ethylene oxide) - lithium trifluoromethanesulfonate complexes," Macromolecules, vol. 28, no. 15, pp. 53125319, 1995.

[53] S. L. Hager and T. B. Macrury, "Investigation of phase behavior and water binding in poly(alkylene oxide) solutions," Journal of Applied Polymer Science, vol. 25, no. 8, pp. 1559-1571, 1980.

[54] M. J. Hey and S. M. Ilett, "Poly(ethylene oxide) hydration studied by differential scanning calorimetry," Journal of the Chemical Society, Faraday Transactions, vol. 87, no. 22, pp. 36713675, 1991.

[55] I. Noda, "Two-dimensional infrared (2D IR) spectroscopy: theory and applications," Applied Spectroscopy, vol. 44, pp. 550$561,1990$.

[56] I. Noda, "Generalized two-dimensional correlation method applicable to infrared, Raman, and other types of spectroscopy," Applied Spectroscopy, vol. 47, pp. 1329-1336, 1993.

[57] Y.-L. Su, H.-Z. Liu, J. Wang, and J.-Y. Chen, "Study of salt effects on the micellization of PEO-PPO-PEO block copolymer in aqueous solution by FTIR spectroscopy," Langmuir, vol. 18, no. 3, pp. 865-871, 2002. 
[58] Y.-L. Su, J. Wang, and H.-Z. Liu, "FTIR spectroscopic investigation of effects of temperature and concentration on PEOPPO-PEO block copolymer properties in aqueous solutions," Macromolecules, vol. 35, no. 16, pp. 6426-6431, 2002.

[59] C. Guo, H. Z. Liu, and J. Y. Chen, "A Fourier transform infrared study of the phase transition in aqueous solutions of ethylene oxide-propylene oxide triblock copolymer," Colloid and Polymer Science, vol. 277, no. 4, pp. 376-381, 1999.

[60] A. Anwer and A. H. Windle, "Magnetic orientation and microstructure of main-chain thermotropic copolyesters," Polymer, vol. 34, no. 16, pp. 3347-3357, 1993.

[61] P. C. M. Christianen, I. O. Shklyarevskiy, M. I. Boamfa, and J. C. Maan, "Alignment of molecular materials in high magnetic fields," Physica B, vol. 346-347, no. 1-4, pp. 255-261, 2004.

[62] M. S. Al-Haik and M. Y. Hussaini, "Molecular dynamics simulation of reorientation of polyethylene chains under a high magnetic field," Molecular Simulation, vol. 32, no. 8, pp. 601-608, 2006.

[63] P. Mukerjee, "The nature of the association equilibria and hydrophobic bonding in aqueous solutions of association colloids," Advances in Colloid and Interface Science, vol. 1, pp. 241275, 1967.

[64] L. Jia, C. Guo, L. Yang et al., "Mechanism of PEO-PPO-PEO micellization in aqueous solutions studied by two-dimensional correlation FTIR spectroscopy," Journal of Colloid and Interface Science, vol. 345, no. 2, pp. 332-337, 2010. 

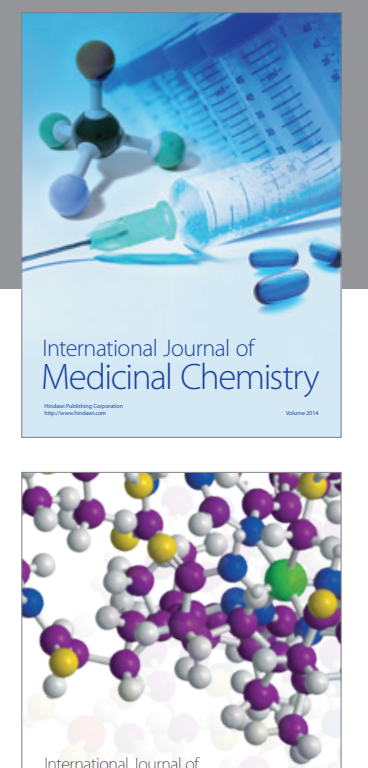

\section{Carbohydrate} Chemistry

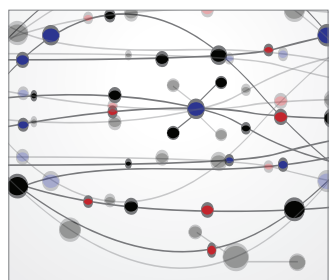

The Scientific World Journal
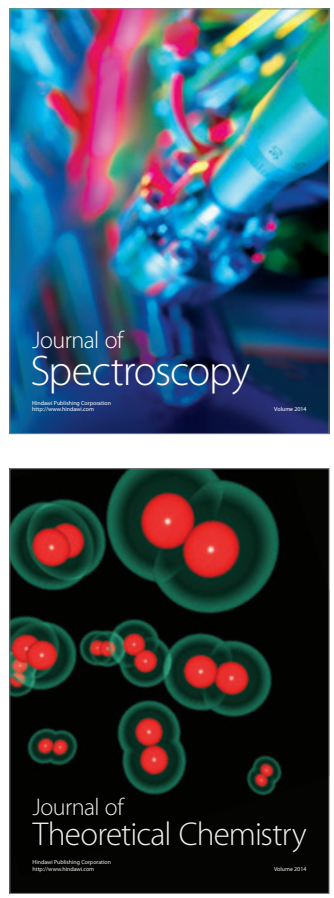
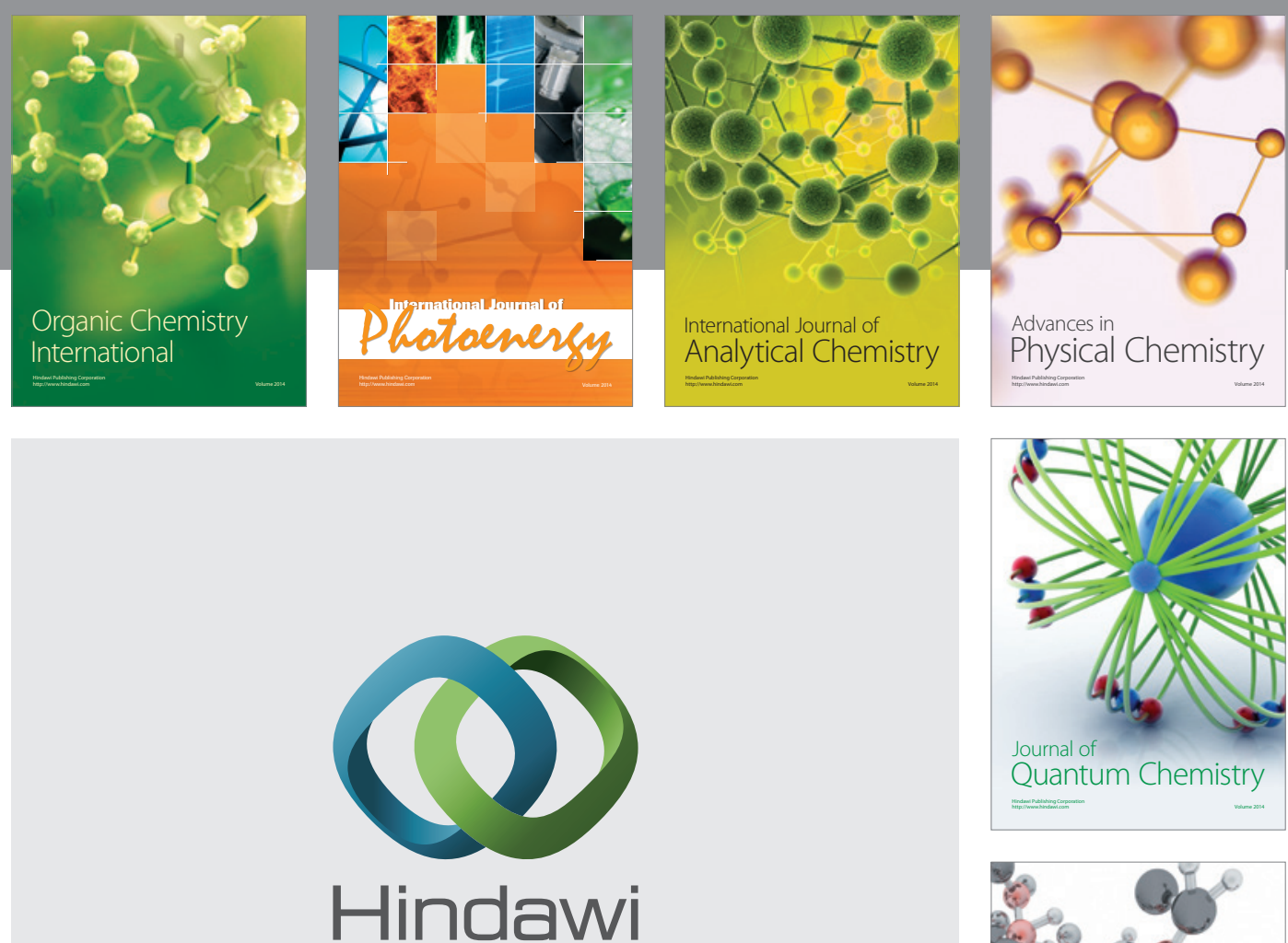

Submit your manuscripts at

http://www.hindawi.com

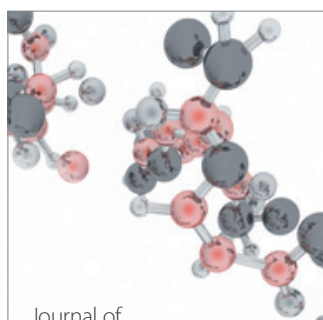

Analytical Methods

in Chemistry

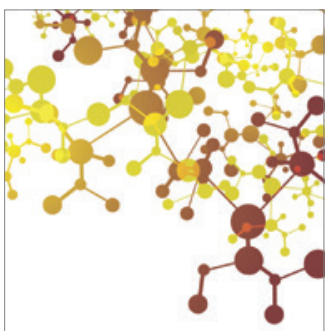

Journal of

Applied Chemistry

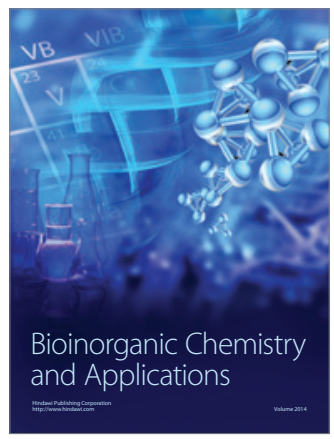

Inorganic Chemistry
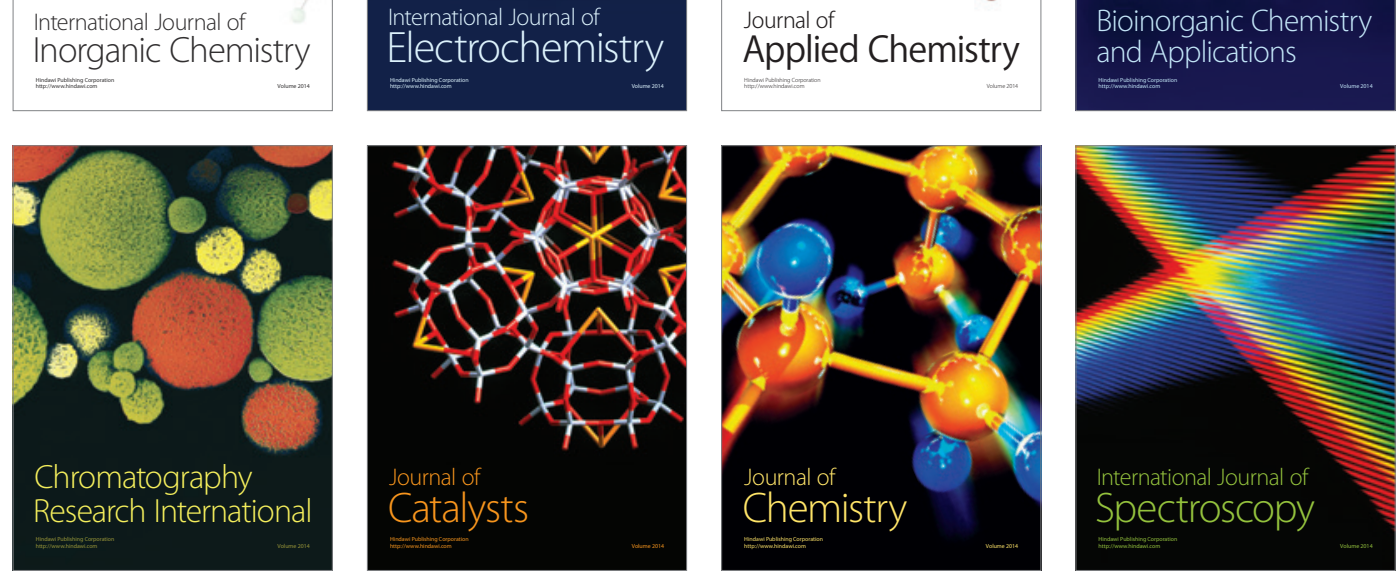